\title{
Replication of IFDO on a chemically defined medium
}

\author{
D. W. BURDON*, JACQUELINE G. WAKEMAN and PAMELA NAYYAR
}

\author{
Department of Microbiology, The General Hospital, Birmingham B4 $6 \mathrm{NH}$
}

\begin{abstract}
An agar or liquid medium containing haemoglobin, high density horse lipoprotein, trypsin, Tween 80, phosphate buffer, $\mathrm{CaCl}_{2}$, glucose, glutamic acid and $\mathrm{NaCl}$ supported growth of ileal fluid dependent organism (IFDO). Glucose, glutamic acid and $\mathrm{NaCl}$ were not essential but enhanced growth. Trace amounts of lipoprotein were sufficient to support growth, and some human sera and serum fractions rich in low density lipoprotein could be substituted for horse lipoprotein. Addition of lipase enhanced the growth rate, and reduced the requirement for lipoprotein. No nucleic acid precursors were identified as essential for growth. However, nucleosides, especially cytidine, accelerated the growth rate. The growth rate was also increased by DNAase and RNAase. These observations indicate that the organisation of the IFDO particle is more complex than that of a crystal. They are consistent with the hypothesis that IFDO is a replicating agent that utilises specific preformed protein to assemble a proteinaceous particle, and support the postulated relationship of IFDO to transmissible spongiform encephalopathy agents.
\end{abstract}

\section{Introduction}

Ileal fluid dependent organism (IFDO) is a novel replicating agent which has the cultural characteristics of a micro-organism, but may be an artefact formed by crystallisation [1]. Evidence against it being a crystal is that it contains protein, lipid and RNA components, each of which is essential for viability. Because of its small size and analogy with transmissible spongiform encephalopathy (TSE) agents with which it shares certain physical and chemical properties [1], it was considered possible that IFDO does not synthesise any protein, and that its protein component might be derived entirely from the medium.

The objectives in developing a chemically defined medium were firstly to establish whether a specific protein was an essential requirement for replication of the agent, and secondly to determine whether there was evidence of a requirement for multiple growth factors, including nucleic acid precursors.

The experiments described were designed to identify substitutes for the mycoplasma agar base, yeast extract, pancreatin, lysed red blood cells and horse serum used in the original growth medium [1].

Received 21 April 1995; revised version accepted 18 Nov. 1995.

*Present address for correspondence: Dr D. W. Burdon, Department of Microbiology, Selly Oak Hospital, Birmingham B29 6JD.

\section{Materials and methods}

Substitution for mycoplasma base medium and yeast extract

Mixtures and individual amino acids or vitamins, or both, were substituted for mycoplasma base, yeast extract, or both, in agar media at the stated concentration, and tested for their ability to support growth of IFDO. The amino acids were L-cysteine $40 \mathrm{mg} / \mathrm{L}$; glycine, L-histidine, and L-tryptophan $90 \mathrm{mg} / \mathrm{L}$; tyrosine $100 \mathrm{mg} / \mathrm{L}$; L-alanine, L-arginine, L-methionine, Lphenylalanine and L-threonine $180 \mathrm{mg} / \mathrm{L} ; \mathrm{L}$-aspartic acid, L-isoleucine, L-lysine, L-proline, L-serine and Lvaline $270 \mathrm{mg} / \mathrm{L}$; L-leucine $360 \mathrm{mg} / \mathrm{L}$; L-glutamic acid $720 \mathrm{mg} / \mathrm{L}$. The vitamins were B12 $5 \mu \mathrm{g} / \mathrm{L}$; biotin and folic acid $12.5 \mu \mathrm{g} / \mathrm{L}$; para-amino benzoic acid $50 \mu \mathrm{g} / \mathrm{L}$; calcium pantothenate, nicotinamide, pyroxidine, riboflavin and thiamine $1 \mathrm{mg} / \mathrm{L}$. Mineral salts and sodium

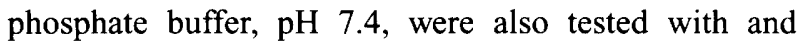
without the amino acids and vitamins. The mineral salts were $\mathrm{NaCl} 0.89 \mathrm{~g} / \mathrm{L} ; \mathrm{CaCl}_{2} 26 \mathrm{mg} / \mathrm{L}, \quad \mathrm{MgCl}_{2}$ $20 \mathrm{mg} / \mathrm{L}, \quad \mathrm{CoCl}_{2} 1 \mathrm{mg} / \mathrm{L}, \quad \mathrm{FeSO}_{4} 4 \mathrm{mg} / \mathrm{L}, \quad \mathrm{MnCl}_{2}$ $20 \mathrm{mg} / \mathrm{L}, \mathrm{CuSO}_{4} 17 \mathrm{mg} / \mathrm{L}$ and $\mathrm{ZnSO}_{4} 4 \mathrm{mg} / \mathrm{L}$.

\section{Substitution for lysed red blood cells}

Horse red blood cells were washed three times with normal saline and lysed with a volume of water equal to half the volume of packed red cells. Three $\mathrm{ml}$ of the lysed red cells were applied to a column of Sephadex G150 (Pharmacia) $80 \times 2.5 \mathrm{~cm}$ and eluted with $0.2 \mathrm{M}$ tris- $\mathrm{HCl}$ buffer, $\mathrm{pH} 8.0$, in $0.14 \mathrm{M} \mathrm{NaCl}$, and containing 
$0.1 \mathrm{M}$ sodium azide, gentamicin, vancomycin, colistin and trimethoprim. Fractions from the haemoglobincontaining peak were pooled and concentrated 10-fold by negative pressure ultrafiltration with $8 / 32$ Visking dialysis tubing (Scientific Instrument Centre), dialysed against water and sterilised by membrane filtration $(0.2 \mu \mathrm{m}$, Sartorius)

In experiments to identify nucleic acid precursors the concentrated haemoglobin was dialysed against $2.0 \mathrm{M}$ $\mathrm{NaCl}$ and incubated with DNAase II (Sigma, D4138) overnight at $37^{\circ} \mathrm{C}$, fractionated on Sephadex and reconcentrated. Then it was incubated with RNAase A (Sigma, R5503) and DNAase I (Sigma, D5025) with $10 \mathrm{mM} \mathrm{MgCl}_{2}$, refractionated on Sephadex G150, and prepared as described previously.

\section{Substitution for pancreatin}

Bovine trypsin (Sigma, T8253) and chymotrypsin (Sigma, C4129) were tested as substitutes for pancreatin at various concentrations. Lipase (Sigma, L1754) from Candida cylindracea, RNAase and DNAase were also tested separately and in combination with trypsin or chymotrypsin.

\section{Substitution for horse serum}

The precipitate formed by mixing 1 volume of horse serum and 4 volumes of ammonium sulphate $50 \%$ was dissolved in saline, dialysed against saline, sterilised by membrane filtration and fractionated on Sephadex G150. Fractions that supported growth of IFDO were detected by adding fractions to wells cut in IFDO medium deficient in horse serum, inoculating with IFDO and incubating at $37^{\circ} \mathrm{C}$.

Electrophoresis of horse serum was done in agarose $1 \%$ in barbitone buffer, $\mathrm{pH} 8.0$, on a glass microscope slide. Then the glass slide was placed in a petri dish, overlayered with IFDO medium deficient in horse serum, inoculated with IFDO and incubated at $37^{\circ} \mathrm{C}$.

Horse and human lipoproteins were prepared by the method of Burstein et al. [2], with sodium phosphotungstate and $\mathrm{MgCl}_{2}$ for high density lipoprotein (HDL), and with heparin and $\mathrm{MgCl}_{2}$ for preparation of low density lipoprotein (LDL). The preparations were further purified by gel filtration on a Bio-Gel A$5 \mathrm{~m}$ agarose column [3].

\section{Nucleic acid precursors}

A variety of ribo- and deoxyribo-nucleosides and nucleotides were tested over a range of concentrations for their effect on growth of IFDO in defined media containing haemoglobin, lipoprotein, trypsin or chymotrypsin, glutamic acid, $\mathrm{CaCl}_{2}$, phosphate buffer and Tween 80. These experiments were repeated with purified haemoglobin, and lipoprotein which had been stored for $>2$ years at $4^{\circ} \mathrm{C}$.

Eluates and filtrates of IFDO grown on defined medium without addition of any nucleosides or nucleotides were tested for susceptibility to RNAase and zinc nitrate as described previously [1]

\section{Results}

\section{Substitution for mycoplasma base}

Growth of IFDO occurred when yeast extract was omitted from the IFDO medium, but not if mycoplasma base was excluded. Medium in which all of the amino acids, vitamins and mineral salts listed were substituted for mycoplasma agar did not support growth. When individual amino acids, vitamins and mineral salts were added to wells cut in an inoculated plate of IFDO agar, glutamic acid, cysteine and tyrosine were found to inhibit growth. Substitution for mycoplasma base with amino acids, vitamins, and mineral salts without these inhibitory amino acids still failed to support growth. Addition of phosphate buffer to this mixture, and to mineral salts alone, allowed growth to occur. Of the mineral salts, $\mathrm{CaCl}_{2}$ was essential for growth, and $\mathrm{NaCl}$ enhanced growth but was not essential. Growth was highly concentration dependent, and the formulation shown in Table 1 was optimal. Subsequent experiments utilised this formulation (medium 1). Growth of IFDO on medium 1 gave colonies that were slightly smaller than those on the previously described IFDO medium [1] after incubation for $48 \mathrm{~h}$.

\section{Substitution for lysed blood}

The only fractions of lysed blood prepared by gel filtration that supported growth of IFDO were those containing haemoglobin (Fig. 1). Growth was also supported when horse haemoglobin purified by being

Table 1. IFDO medium 1, prepared by adding $15 \mathrm{ml}$ of bacteriological agar containing Tween 80 at $56^{\circ} \mathrm{C}(\mathrm{A})$, to a petri dish containing the ingredients listed (B)

\begin{tabular}{|c|c|c|}
\hline $\mathrm{A}$ & $\begin{array}{l}\text { Oxoid Bacteriological agar } \\
\text { Tween } 80 \\
\text { Made up to } 1 \mathrm{~L} \text { with distilled water } \\
\text { Dispensed in } 15-\mathrm{ml} \text { volumes and autoclaved }\end{array}$ & $\begin{array}{l}25.0 \mathrm{~g} \\
20 \mathrm{ml}\end{array}$ \\
\hline B & $\begin{array}{l}\text { Lysed blood* } \\
\text { Horse serum } \\
\text { Freshly prepared pancreatin } \\
1.0 \mathrm{M} \text { sodium phosphate buffer, } \mathrm{pH} 7.4^{\ddagger} \\
\text { Calcium chloride }(39 \mathrm{mg} \text { in } 10 \mathrm{ml} \text { of water })^{\ddagger} \\
2.0 \mathrm{M} \text { sodium chloride } \\
\text { Activated glutaraldehyde } 2 \%^{\ddagger} \\
\text { Thallium acetate } 2 \% \%^{\ddagger}\end{array}$ & $\begin{array}{l}0.3 \mathrm{ml} \\
0.02 \mathrm{ml} \\
0.3 \mathrm{ml} \\
0.1 \mathrm{ml} \\
0.1 \mathrm{ml} \\
0.5 \mathrm{ml} \\
0.1 \mathrm{ml} \\
0.1 \mathrm{ml}\end{array}$ \\
\hline
\end{tabular}

* Prepared from horse red blood cells washed three times with normal saline.

${ }^{\dagger}$ Pancreatin (Sigma, P1500) $2 \mathrm{~g}$ suspended in $20 \mathrm{ml}$ of saline; centrifuged and supernatant sterilised by membrane filtration.

${ }^{\ddagger}$ These ingredients were not allowed to mix in the petri dish before addition of the agar. 
crystallised three times (Sigma, H4632) was substituted for lysed blood.

\section{Substitution for pancreatin}

Both trypsin and chymotrypsin supported growth of IFDO, when substituted for pancreatin in mycoplasma agar base with lysed blood. An appropriate concentration for both enzymes was $0.1 \mathrm{mg} / \mathrm{ml}$. Addition of lipase at a concentration of $0.2 \mathrm{mg} / \mathrm{ml}$, in addition to the protease, further improved growth but was not essential. Similarly, the rate of growth was increased when RNAase or DNAase was added.

\section{Substitution for horse serum}

Growth of IFDO occurred with the ammonium sulphate precipitate of horse serum that had been redissolved and dialysed. The elution position of protein fractions obtained by gel filtration of this material is shown in Fig. 1. Peak activity was present in fractions eluting just in advance of haemoglobin, indicating a mol. wt in the region of $70000-150000$.

When agarose gels containing electrophoresed horse serum were over-layered with serum-deficient IFDO agar, growth of IFDO occurred in the vicinity of a protein with alpha mobility.

These physical properties and the known susceptibility of IFDO to inactivation by lipase, suggested a possible identification of the essential growth-supporting protein as a lipoprotein.

Horse HDL prepared by sodium phosphotungstate and $\mathrm{MgCl}_{2}$ precipitation followed by gel filtration supported growth of IFDO. Human LDL prepared by heparin and $\mathrm{MgCl}_{2}$ precipitation also supported

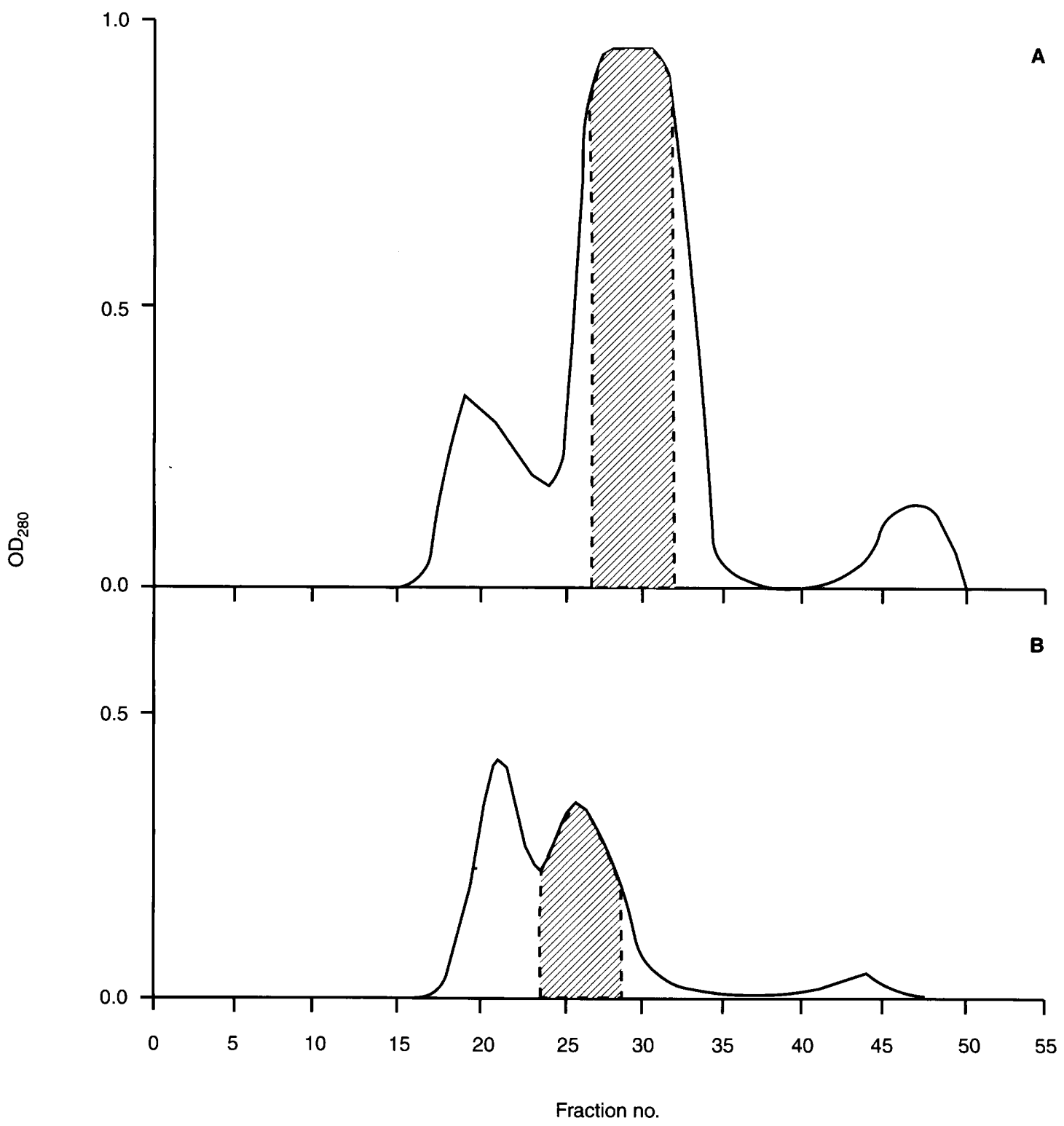

Fig. 1. Gel filtration on Sephadex G150 of: (A), lysed washed horse red cells; (B), redissolved ammonium sulphate precipitate of horse serum. Hatched areas contained proteins that supported growth of IFDO. In A, this corresponded to fractions containing haemoglobin. 
growth, but agarose gel filtration of this material resulted in loss of growth-supporting activity. On immuno-electrophoresis, horse HDL and human LDL gave a single precipitin line with appropriate wholeserum antisera. Immuno-diffusion in agar with an antiserum to human LDL showed a weak precipitation with horse serum and a possible reaction of partial identity between horse and human lipoprotein (Fig. 2.)

\section{Growth on defined medium}

When medium 1 was prepared with trypsin or chymotrypsin, haemoglobin and lipoprotein, growth of IFDO was poor and barely visible after incubation for several days. The finding of slower growth with purified materials and enzymes indicated that there might be a relative deficiency of low mol. wt substances, and the requirement for these was reevaluated. Increasing the amount of $\mathrm{CaCl}_{2}$ added to each petri dish improved the growth rate. Growth was also improved by each of the amino acids, glutamic acid, aspartic acid, cysteine and glycine. These enhanced growth at appropriate concentrations but inhibited it at higher concentrations. The best growth was obtained by addition of $0.5 \mathrm{ml}$ of glutamic acid $(6 \mathrm{~g} / \mathrm{L})$ dissolved by boiling, to $15 \mathrm{ml}$ of agar medium. Addition of $0.5 \mathrm{ml}$ glucose $(0.5 \mathrm{~g} / \mathrm{ml})$ also improved growth.

The final composition of defined medium is given in

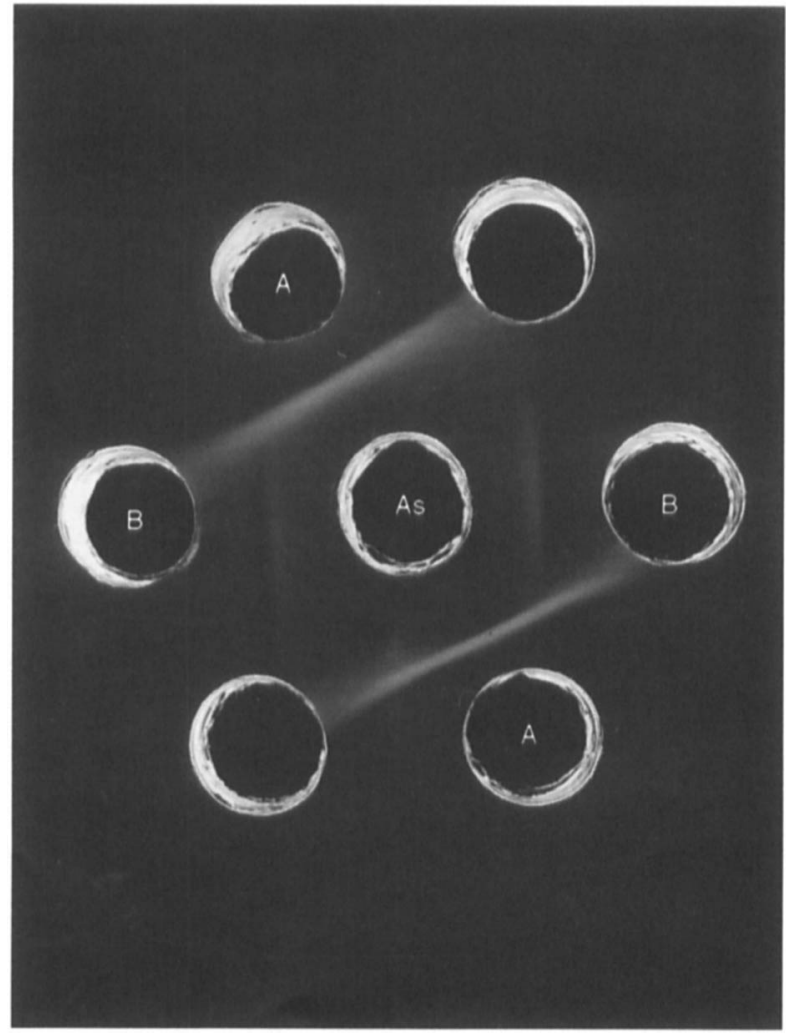

Fig. 2. Precipitation of human lipoprotein (A) and horse lipoprotein (B) by antiserum to human low density lipoprotein (AS).
Table 2. IFDO defined medium, prepared by adding $15 \mathrm{ml}$ of bacteriological agar containing Tween 80 at $56^{\circ} \mathrm{C}(\mathrm{A})$, to a petri dish containing the ingredients listed (B)

\begin{tabular}{lll}
\hline A & $\begin{array}{l}\text { Oxoid Bacteriological agar } \\
\text { Tween } 80\end{array}$ & $25.0 \mathrm{~g}$ \\
& $20 \mathrm{ml}$ \\
& Made up to 1 L with distilled water \\
& Dispensed in 15-ml volumes and autoclaved & \\
& & \\
B & Haemoglobin* & \\
& Horse lipoprotein* & $0.1 \mathrm{ml}$ \\
Trypsin or chymotrypsin $(15 \mathrm{mg} / \mathrm{ml})$ & $0.1 \mathrm{ml}$ \\
1.0 M sodium phosphate buffer, pH $7.4^{\ddagger}$ & $0.5 \mathrm{ml}$ \\
Calcium chloride $(39 \mathrm{mg} \text { in } 10 \mathrm{ml} \text { of water })^{\ddagger}$ & $0.5 \mathrm{ml}$ \\
2.0 M Sodium chloride & $0.5 \mathrm{ml}$ \\
Glucose solution $50 \%$ & $0.5 \mathrm{ml}$ \\
Glutamic acid & \\
Thallium acetate $2 \% \ddagger$ & $0.1 \mathrm{ml}$
\end{tabular}

* See methods for preparation. Amounts used varied with different preparations.

†Prepared by dissolving glutamic acid $60 \mathrm{mg}$ in $10 \mathrm{ml}$ of water by boiling.

${ }^{\ddagger}$ These ingredients were not allowed to mix in the petri dish before addition of the agar.

Table 2. Growth failed if haemoglobin, proteolytic enzyme, Tween $80, \mathrm{CaCl}_{2}$ or phosphate was omitted. If lipoprotein was omitted, growth was delayed for several days, but if lipase was substituted, early growth was restored.

\section{Nucleic acid precursors}

The medium specified in Table 2 gave good growth of IFDO in 2 days, which was not improved by addition of nucleosides and nucleotides. Growth was not altered by treatment of the haemoglobin and lipoprotein preparations with nucleases and repeated gel filtration. Reduction of the amounts of haemoglobin, lipoprotein and chymotrypsin to the lowest concentration able to support growth reduced the growth rate, but growth still occurred without nucleosides or nucleotides. When nucleosides and nucleotides were added individually or collectively to wells cut into agar plates containing medium 2, growth sometimes occurred more rapidly in the neighbourhood of the wells. This was especially apparent with cytidine, and was more easily demonstrated when the preparations of haemoglobin and lipoprotein used had been stored for several weeks. However, experiments with protein preparations that had been stored for longer periods of 2-3 years at $4^{\circ} \mathrm{C}$ failed to give unequivocal evidence of a requirement for nucleosides or nucleotides. Eluates and filtrates of IFDO grown on defined medium without added nucleosides and nucleotides showed the same susceptibility to inactivation by $\mathrm{RNAase}$ and $\mathrm{Zn}\left(\mathrm{NO}_{3}\right)_{2}$ as IFDO grown on the original medium containing mycoplasma agar base and yeast extract [1].

\section{Discussion}

The identification of five substances essential for growth of IFDO indicates a simple organisation, but 
nevertheless one of greater complexity than that of a crystal. It has been proposed previously that IFDO is a self-replicating nucleic acid which identifies, captures and utilises pre-formed, host-derived protein to assemble a proteinaceous particle [1]. On the basis of several shared and unusual physico-chemical properties, a relationship between IFDO and the agents responsible for Creutzfeldt-Jakob disease in man, scrapie in sheep and related human and animal encephalopathies (TSE agents) was suggested. At present there are insufficient data to speculate usefully on how the substances required for replication of IFDO initiate replication, but it has been observed that the addition of some of these to the agent can alter its physico-chemical properties (Burdon, unpublished data). This has been interpreted to indicate that IFDO replicates by a sequence of chemical reactions in which these substances are utilised in turn. Haemoglobin appears to play a central role in this sequence.

The most significant findings from the development of the defined medium are that haemoglobin is required in large amounts for replication of IFDO, and trace amounts of lipoprotein are also utilised. These requirements for pre-formed protein are consistent with identification of IFDO as a TSE-like agent, and suggest that haemoglobin may be the principal source of the protein component of IFDO.

In the case of scrapie, purification of the agent from infected brain led to the identification of a glycoprotein designated $\operatorname{PrP} 27-30$, of mol. wt $27-30 \mathrm{kDa}$. This protein co-purifies with infectivity and was named a prion [4]. Sequencing of the N-terminal amino acids of the prion [5] enabled a PrP 27-30 cDNA to be assembled, which was found to code for a normal membrane protein ( $\mathrm{PrP}^{33-35 c}$, abbreviated to $\operatorname{PrP}^{c}$ ) of unknown function [6]. In scrapie a modified form of the protein $\left(\mathrm{PrP}^{33-35 s c}\right.$ or $\left.\mathrm{PrP}^{s c}\right)$ accumulates, which differs from the normal isoform $\mathrm{PrP}^{c}$ in being partially resistant to proteolytic digestion by proteinase $\mathrm{K}$. Digestion of $\mathrm{PrP}^{s c}$ with proteinase $\mathrm{K}$ converts it to PrP 27-30 [7]. Therefore, it appeared that the prion was derived from a host-synthesised protein by posttranslational modification. Confirmation of this was provided by experiments with mice devoid of PrP precursor gene. Such mice were apparently normal [8] and when inoculated with mouse or hamster prions remained well, whereas mice with the gene developed scrapie [9].

The requirement of IFDO for lipoprotein is another point of similarity with TSE agents as apolipoprotein $E$ has been found in association with amyloid plaques in Creutzfeldt-Jakob disease [10], and evidence of a lipid component in scrapie prion preparations has been described [11]. Interestingly, lipoprotein is associated with other disorders, such as Alzheimer's disease $[10,12]$, in which there has been speculation on a possible association with TSE-like agents.
Whereas the brown pigmented colonies of IFDO suggest that an iron-containing moiety of haemoglobin is incorporated in the IFDO particle, it is not clear whether lipoprotein is also included within the particle. The action of lipase in enhancing growth and reducing the requirement for lipoprotein suggests that the substrate utilised during growth might be a fatty acid or lipid rather than lipoprotein. A lipid component which was essential for the integrity of the particle would also explain the susceptibility of IFDO to inactivation by higher concentrations of lipase than those used for growth.

The inability to demonstrate a requirement for nucleic acjd precursors was disappointing. However, IFDO colonies grown on defined medium were indistinguishable from IFDO colonies grown on the original medium and their viability was RNA-dependent. It seems that RNA precursors must have contaminated the defined medium in sufficient quantities to fulfill the growth requirements of IFDO. Their presence is due to the difficulty in preparing nucleic acid-free and nucleotide-free reagents from biological materials.

In conclusion, the data presented are consistent with IFDO being a primitive biological agent with a nucleic acid which does not encode for any other macromolecule, but which can recognise haemoglobin and utilise it to assemble a proteinaceous particle. These observations reinforce the hypothesis that IFDO is a TSE-like agent and that it provides a valid model for investigating the nature of TSE agents [1].

This study was partly funded by grants from the Endowment Fund of the former United Birmingham Hospitals and the Bicentenary Research Fund of The General Hospital.

\section{References}

1. Burdon DW. A novel replicating agent isolated from the human intestinal tract having characteristics shared with CreutzfeldtJakob and related agents. $J$ Med Microbiol 1989; 29: 145-157.

2. Burstein M, Scholnick HR, Morfin R. Rapid method for the isolation of lipoproteins from human serum by precipitation with polyanions. J Lipid Res 1970; 11: 583-595.

3. Rudel LL, Lee JA, Morris MD, Felts JM. Characterization of plasma lipoproteins separated and purified by agarose-column chromatography. Biochem $J$ 1974; 139: 89-95.

4. Bolton DC, McKinley MP, Prusiner SB. Identification of a protein that purifies with the scrapie prion. Science $1982 ; 218$ : 1309-1311.

5. Prusiner SB, Groth DF, Bolton DC, Kent SB, Hood LE. Purification and structural studies of a major scrapie prion protein. Cell 1984; 38: 127-134.

6. Oesch, B, Westaway D, Wälchli $\mathrm{M}$ et al. A cellular gene encodes scrapie PrP 27-30 protein. Cell 1985; 40: 735-746.

7. Prusiner SB, Bolton DC, Groth DF, Bowman KA, Cochran SP, McKinley MP. Further purification and characterization of scrapie prions. Biochemistry 1982; 21: 6942-6950.

8. Büeler H, Fischer M, Lang $\mathrm{Y}$ et al. Normal development and behaviour of mice lacking the neuronal cell-surface $\operatorname{PrP}$ protein. Nature 1992; 356: 577-582.

9. Büeler H, Aguzzi A, Sailer A et al. Mice devoid of $\operatorname{PrP}$ are resistant to scrapie. Cell 1993; 73: 1339-1347.

10. Namba Y, Tomonaga M, Kawasaki H, Otomo E, Ikeda K. 
Apolipoprotein E immunoreactivity in cerebral amyloid deposits and neurofibrillary tangles in Alzheimer's disease and kuru plaque amyloid in Creutzfeldt-Jakob disease. Brain Research 1991; 541: 163-166.

11. Prusiner SB, Hadlow WJ, Eklund CM, Race RE, Cochran SP
Sedimentation characteristics of the scrapie agent from murine spleen and brain. Biochemistry 1978; 17: 4987-4992.

12. Wisniewski T, Frangione B. Apolipoprotein E: a pathological chaperone protein in patients with cerebral and systemic amyloid. Neurosci Lett 1992; 135: 235-238. 